\title{
On the misuse of "weighted" composite scores: the scoring procedure of the FEED questionnaire does not indicate whether it is necessary to differentiate between the frequency of experiencing an emotion and the desire to eat in response to that emotion in the assessment of emotional eating
}

\author{
Adrian Meule ${ }^{1,2}$ (D) \\ Received: 31 August 2021 / Accepted: 1 September 2021 / Published online: 12 September 2021 \\ (c) The Author(s) 2021
}

Recently, Cassioli et al. [1] developed the Florence Emotional Eating Drive (FEED) questionnaire for the assessment of emotional eating. In contrast to existing emotional eating questionnaires, the FEED not only assesses how strong the desire to eat is in response to different emotions, but also how often this emotion is experienced in the first place. This procedure may provide valuable information as emotional eating may not be a big issue for someone who has a strong desire to eat in response to certain emotions but rarely experiences these emotions. Thus, considering this frequency may increase validity of emotional eating questionnaires, which do not seem to predict actual food intake reliably [2].

Scores of the frequency and the desire to eat subscale are recorded on 5-point scales ranging from 0 to 4 . However, the authors then created a scoring procedure that recodes scores from both subscales to a 10-point scale ranging from 0 to 9 . For example, a score of 4 on the frequency scale and a score of 4 on the desire to eat scale would be recoded to 9 . Yet, the weighting algorithm remains elusive as it is not a simple summation, averaging, or multiplication of scores. Yet, even if the weighting algorithm would be different, such a scoring procedure does not provide any information whether it is actually necessary to assess the frequency of experiencing an emotion and the desire to eat in response to that emotion separately and whether there should be a weighted combination of scores.

Adrian Meule

ameule@med.lmu.de

1 Department of Psychiatry and Psychotherapy, University Hospital, LMU Munich, Munich, Germany

2 Schoen Clinic Roseneck, Am Roseneck 6, 83209 Prien am Chiemsee, Germany
Using composite scores has been criticized decades ago [3], but they are still tenaciously used by researchers. Examples include measures of quality of life [4], rejection sensitivity [5], or intrusion load [6], for which two variables are multiplied to create weighted composite scores. However, such scores create several problems in interpretation and do actually not answer the question that researchers are interested in [7, 8]. As an example, let us consider the correlation between the FEED total score and body mass index (BMI). The coefficient is $r=0.14$, indicating a small, positive relationship. However, it is unknown whether this relationship is primarily due to the frequency subscale, the desire to eat subscale, or their combination. To test this, the easiest way would be to use moderated regression analysis [9, 10], in which BMI is predicted by three independent variables: frequency scores, desire to eat scores, and their product term (frequency $\times$ desire to eat). If the interaction term is significant, this would indicate that the size (or direction) of the relationship between desire to eat scores and BMI depends on frequency scores (or vice versa, that the relationship between frequency scores and BMI depends on desire to eat scores). For example, the nature of the interaction effect may be that a higher desire to eat in response to certain emotions relates to higher BMI but only in those with high frequency scores, showing that the combination of both subscales does indeed provide meaningful information. If the interaction effect is not significant, it is still possible that the frequency and desire to eat subscale have additive effects (i.e., both may independently relate to BMI). However, it may also be that the association between emotional eating and BMI is driven only by one subscale.

To conclude, the way that the FEED questionnaire is constructed may indeed lead to new insights for the assessment of emotional eating. However, the scoring procedure that 
is currently used does not provide these insights. Instead of creating composite scores, scores of both FEED subscales should be used both separately and interactively in moderated regression analyses or other types of statistical procedures, in which such effects can be tested (e.g., structural equation modeling). Only such analyses can reveal whether it is actually necessary to consider the frequency of how often an emotion is experienced and the desire to eat in response to that emotion separately and in combination. However, such analyses may also reveal that one of these subscales suffices in the assessment of emotional eating.

Funding Open Access funding enabled and organized by Projekt DEAL.

\section{Declarations}

Conflict of interest The author declares that there is no conflict of interest.

Ehtical approval This article does not report any studies with human participants or animals performed by any of the authors.

Informed consent This article does not report any studies with human participants performed by any of the authors.

Open Access This article is licensed under a Creative Commons Attribution 4.0 International License, which permits use, sharing, adaptation, distribution and reproduction in any medium or format, as long as you give appropriate credit to the original author(s) and the source, provide a link to the Creative Commons licence, and indicate if changes were made. The images or other third party material in this article are included in the article's Creative Commons licence, unless indicated otherwise in a credit line to the material. If material is not included in the article's Creative Commons licence and your intended use is not permitted by statutory regulation or exceeds the permitted use, you will need to obtain permission directly from the copyright holder. To view a copy of this licence, visit http://creativecommons.org/licenses/by/4.0/.

\section{References}

1. Cassioli E, Calderani E, Fioravanti G, Lazzeretti L, Rotella CM, Rossi E et al (2021) The Florence emotional eating drive (FEED): a validation study of a self-report questionnaire for emotional eating. Eat Weight Disord. https://doi.org/10.1007/s40519-02101216-2 (In press)

2. Bongers P, Jansen A (2016) Emotional eating is not what you think it is and emotional eating scales do not measure what you think they measure. Front Psychol 7(1932):1-11. https://doi.org/ 10.3389/fpsyg.2016.01932

3. Evans MG (1991) The problem of analyzing multiplicative composites: interactions revisited. Am Psychol 46(1):6-15. https:// doi.org/10.1037/0003-066X.46.1.6

4. Cummins RA, Mccabe MP, Romeo Y, Gullone E (1994) The comprehensive quality of life scale (Comqol): instrument development and psychometric evaluation on college staff and students. Educ Psychol Meas 54(2):372-382. https://doi.org/10.1177/00131 64494054002011

5. Downey G, Feldman SI (1996) Implications of rejection sensitivity for intimate relationships. J Pers Soc Psychol 70(6):13271343. https://doi.org/10.1037/0022-3514.70.6.1327

6. Rattel JA, Miedl SF, Franke LK, Grünberger LM, Blechert J, Kronbichler M et al (2019) Peritraumatic neural processing and intrusive memories: the role of lifetime adversity. Bio Psychiatry Cogn Neurosci Neuroimaging 4:381-389. https://doi.org/10. 1016/j.bpsc.2018.12.010

7. Trauer T, Mackinnon A (2001) Why are we weighting? The role of importance ratings in quality of life measurement. Qual Life Res 10:579-585. https://doi.org/10.1023/A:1013159414364

8. Rohrer JM, Schmukle SC (2018) Individual importance weighting of domain satisfaction ratings does not increase validity. Collabra Psychol. https://doi.org/10.1525/collabra.116

9. Hayes AF (2018) Introduction to mediation, moderation, and conditional process analysis, 2nd edn. The Guilford Press, New York

10. Hayes AF, Rockwood NJ (2017) Regression-based statistical mediation and moderation analysis in clinical research: observations, recommendations, and implementation. Behav Res Ther 98:39-57. https://doi.org/10.1016/j.brat.2016.11.001

Publisher's Note Springer Nature remains neutral with regard to jurisdictional claims in published maps and institutional affiliations. 